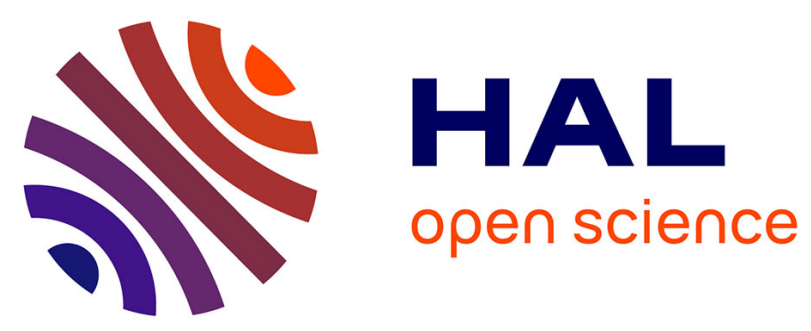

\title{
Flow cytometry evaluation of infection-related biomarkers in febrile subjects in the emergency department
}

Penelope Bourgoin, Guillaume Lediagon, Isabelle Arnoux, Denis Bernot, Pierre-Emmanuel Morange, Pierre Michelet, Fabrice Malergue, Thibaut

Markarian

\section{To cite this version:}

Penelope Bourgoin, Guillaume Lediagon, Isabelle Arnoux, Denis Bernot, Pierre-Emmanuel Morange, et al.. Flow cytometry evaluation of infection-related biomarkers in febrile subjects in the emergency department. Future Microbiology, 2020, 15 (3), pp.189-201. 10.2217/fmb-2019-0256 . hal-03163533

\section{HAL Id: hal-03163533 \\ https://hal-amu.archives-ouvertes.fr/hal-03163533}

Submitted on 9 Mar 2021

HAL is a multi-disciplinary open access archive for the deposit and dissemination of scientific research documents, whether they are published or not. The documents may come from teaching and research institutions in France or abroad, or from public or private research centers.
L'archive ouverte pluridisciplinaire HAL, est destinée au dépôt et à la diffusion de documents scientifiques de niveau recherche, publiés ou non, émanant des établissements d'enseignement et de recherche français ou étrangers, des laboratoires publics ou privés. 


\title{
Flow cytometry evaluation of infection-related biomarkers in febrile subjects in the emergency department
}

\author{
Pénélope Bourgoin ${ }^{1,2}$, Guillaume Lediagon ${ }^{3}$, Isabelle Arnoux ${ }^{4}$, Denis Bernot ${ }^{4}$, \\ Pierre-Emmanuel Morange ${ }^{2,4}$, Pierre Michelet ${ }^{3}$, Fabrice Malergue ${ }^{*, 1}$ (iD) \& Thibaut \\ Markarian ${ }^{3}$ \\ ${ }^{1}$ Department of Research \& Development, Beckman Coulter Life Sciences-Immunotech, 130 Avenue de Lattre de Tassigny, 13009 \\ Marseille, France \\ ${ }^{2}$ C2VN INSERM-INRA, Aix-Marseille University, 27 Boulevard Jean Moulin, 13385 Marseille, France \\ ${ }^{3}$ Adult Emergency Unit, La Timone Hospital, APHM, 264 Rue Saint Pierre, 13385 Marseille, France \\ ${ }^{4}$ Hematology Laboratory, La Timone Hospital, APHM, 264 Rue Saint Pierre, 13385 Marseille, France \\ *Author for correspondence: fmalergue@beckman.com
}

Aim: In an Emergency Department (ED), the etiological identification of infected subjects is essential. 13 infection-related biomarkers were assessed using a new flow cytometry procedure. Materials \& methods: If subjects presented with febrile symptoms at the ED, 13 biomarkers' levels, including CD64 on neutrophils (nCD64) and CD169 on monocytes (mCD169), were tested and compared with clinical records. Results: Among 50 subjects, $78 \%$ had bacterial infections and $8 \%$ had viral infections. nCD64 showed $82 \%$ sensitivity and $91 \%$ specificity for identifying subjects with bacterial infections. mCD169, HLA-ABC ratio and HLA-DR on monocytes had high values in subjects with viral infections. Conclusion: Biomarkers showed promising performances to improve the ED's infectious stratification.

First draft submitted: 9 September 2019; Accepted for publication: 4 February 2020; Published online: 17 February 2020

Keywords: bacterial infection • emergency department • fever $\bullet$ flow cytometry $\bullet$ viral infection

An important medical issue encountered by practitioners in the Emergency Department (ED) is accurate identification of the cause of infection in subjects presenting with fever or febrile symptoms [1]. It is necessary to properly and rapidly treat and manage subjects; indeed, in cases of bacterial infection, antibiotic therapy should be initiated as soon as possible to prevent the infection from evolving to septic shock [2], whereas the use of such treatments in cases of viral infection is ineffective and could even lead to the development of antibiotic resistance [3,4]. Clinical signs are often similar among different pathogens and can even be caused by noninfectious agents. Thus, proper diagnosis must be confirmed by commonly recommended assessments, such as CRP and PCT [5]. However, the sensitivity and specificity of these biomarkers are unclear, particularly when evaluated in subjects with inflammatory syndromes or local infections .

The results of a recent meta-analysis by the Kapasi et al. [6] and of a preliminary retrospective study by the Bourgoin et al. [7] showed the utility of different soluble and cell-based host biomarkers to determine infection etiology. The expression of CD64 on neutrophils (nCD64) is significantly increased in subjects with bacterial infections [8-10]. Conversely, the expression of CD169 on monocytes (mCD169) has not been frequently evaluated in infections, but has recently been shown to be increased in subjects with viral infections [11-14].

Assessment of these markers traditionally uses flow cytometry. However, this technique is unsuitable for simple, rapid analysis in the ED owing to the complexity of the procedure and the materials and labor requirements for preparing samples and using the flow cytometer [15]. Therefore, improved and innovative flow cytometry methods are required [16].

Accordingly, in this single-center, observational, prospective study, the aim was to confirm the relevance of assessing the expressions of both biomarkers in subjects presenting with fever or febrile symptoms at the ED. The hypothesis was that the measurement of these biomarkers, using a novel flow cytometry method, more fitted to

Future $\because$ Medicine 
ED settings, may be able to distinguish between bacterial or viral infection, showing better performance than other cellular biomarkers (e.g., PCT and CRP).

In addition, other host cell surface biomarkers, including CD35 on monocytes (mCD35) and neutrophils (nCD35), CD55 on monocytes (mCD55) and neutrophils ( $\mathrm{CD} 55$ ), CD46 on monocytes (mCD46), the ratio of HLA-ABC on monocytes/neutrophils (rHLA-ABC), CD69 on lymphocytes (ICD69), monocytes (mCD69) and neutrophils (nCD69), CD14 on monocytes (mCD14) and HLA-DR on monocytes (mHLA-DR), have also been studied for their ability to distinguish among bacterial and viral infections [17-19].

For all these evaluations, despite a good recruitment of subjects with bacterial infections, very few subjects with viral infections were included; therefore, the results described in this study regarding the viral group are presented as preliminary data, neither statistically compared nor evaluated for stratification performance.

\section{Materials \& methods}

Prospective inclusion of samples

The study population included subjects older than 18 years attending the adult ED of La Timone University Hospital in Marseille, France, with infectious symptoms. Subjects were enrolled during 15 consecutive days. The inclusion criteria were as follows: fever $\geq 38.0^{\circ} \mathrm{C}$ or hypothermia $>36.5^{\circ} \mathrm{C}$, with other potential respiratory (cough, sputum and dyspnea), urinary (potential urinary infection), abdominal (pain syndrome, diarrhea), cutaneous (erysipelas) or neurological (meningitis) clinical signs. The exclusion criteria were as follows: incomplete clinical files, trauma or subjects presenting with a known inflammatory or autoimmune disease, neoplasia, chronic infectious disease (viral, fungal or bacterial) or antibiotic, antiviral or immunosuppressive treatment prior to admission, and subjects with extensive burns or recent surgery (less than 1 month).

The procedures were in accordance with the ethical standards of the Helsinki Declaration. The Hospital Ethical Committee and the French Committee for Protection of Persons approved this observational and noninterventional prospective study (CPP approval no. 181160; ID-RCB approval no. 2018 A02706-49). Confidentiality was preserved at all levels. Subjects provided informed consent and their routine care was not modified. All data assessed in this study were part of routine clinical practice and retrieved from subject records without any intervention.

\section{Routine sample testing}

Blood samples were sent to the Hematology Laboratory of La Timone Hospital, and processed within $24 \mathrm{~h}$ as part of the standard, routine clinical tests universally performed at the hospital.

White blood cell (WBC) and polymorphonuclear neutrophil (PMN) counts were assessed using a Sysmex XN system (Sysmex Inc., Kobe, Japan). PCT was measured using a Dosage ADVIA Centaur BRAHMS Procalcitonin system (Siemens, Munich, Germany) and CRP was measured using the C-Reactive Protein Gen.3 system (COBAS, Roche, Basel, Switzerland).

For the detection of viruses, blood or cerebrospinal fluid samples were examined with PCR, and serum samples were tested for IgG and IgM using a LIAISON analyzer (DiaSorin, Saluggia, Italy). For the detection of bacteria, blood cultures and bacterial identification were performed using a Bruker Mass Spectrometry system (Brucker Inc., MA, USA), urinary antigen tests (for Pneumococcus and Legionella), PCR (for Chlamydia and Mycoplasma) and/or cultures of respiratory tract secretions (nasopharyngeal swabs, tracheobronchial aspirate or bronchoalveolar lavage).

\section{Clinical data collection}

A team of three ED specialist practitioners, blinded to the study test results, recorded for each subject their epidemiological data (sex, age, clinical history, medical institutionalization, altered mental status), physiological data (cardiac constants, body temperature, vital signs and symptoms, prior administration of antibiotics), biological data (WBC and PMN counts, CRP and PCT levels, biochemical measurements, name of the identified pathogens if isolated) and clinical data (time from onset, symptoms, final diagnosis), and then classify them into three groups. The classification of patients was made by taking into account only the patient's symptoms, the final diagnosis established by the practitioner during the consultation, and possibly the microbiological results of isolations if confirmation was required.

If clinical symptoms and microbiological test results, in addition to final diagnosis, proved no evidence of infection, then subjects were classified as noninfected subjects. If clinical and microbiological findings strongly confirmed the presence of a bacterial infection established by the final diagnosis (positive bacterial culture result and/or negative viral test result), subjects were categorized as having a bacterial infection. Finally, if typical clinical 
symptoms of infection and viral agents were detected, with potential negative bacteriological results and viral final diagnosis, subjects were confirmed as having viral infections. No subjects were co-infected. In cases in which the diagnosis was questionable, a second group of two ED practitioners was consulted and consensus was reached.

\section{Flow cytometry assessment}

Leftover EDTA-treated blood samples were pseudonymized and treated by flow cytometry. Briefly, careful titrations of the following antibodies were performed in accordance with a newly described one-step staining procedure [16]: anti-CD169-phycoerythrin (clone 7-239), anti-CD64-PacificBlue (clone 22), anti-CD35-fluorescein isothyocyanate (clone J3D3), anti-CD55-phycoerythrin (clone JS11KSC2.3), anti-HLA-ABC-Alexa Fluor 700 (clone B9.12.1), recognizing all 3 MHC class-I antigens HLA A, B, and C; anti-CD69-allophycocyanin (clone TP1.55.3), anti-CD14-Krome Orange (clone RMO52) and anti-HLA-DR-PacificBlue (clone Immu357), recognizing the MHC class-II antigen DR, all custom products from Beckman Coulter Inc. (CA, USA), as well as anti-CD46-allophycocyanin (clone TRA-2-10) from Biolegend Inc. (CA, USA). Antibodies were separated in two antibody cocktails and dried at their optimized amounts in two different 5-ml testing tubes, using the DURA Innovations drying process (Beckman Coulter Inc.) [20-25].

For each sample, $500 \mu \mathrm{l}$ Versalyse lysing solution (Beckman Coulter Inc.) and $5 \mu$ l blood were transferred to both tubes. After incubation for $15 \mathrm{~min}$, samples were analyzed on a three-laser, 10-color Navios flow cytometer (Beckman Coulter Inc.). Flow-Set beads (Beckman Coulter) were used before each analytical run in order to control the variability in device performance; however, no harmonization between the measured values over the study period was necessary. Analysis was performed using Kaluza Analysis Software (version 2.1; Beckman Coulter Inc.). Neutrophils, monocytes and lymphocytes were gated on the basis of their typical forward and side-scatter characteristics. The expression levels of each biomarker were determined as mean fluorescence intensities (MFIs).

The influence of medical procedures and diagnosis was prevented by blinding the medical practitioners to the results of flow cytometry analysis.

\section{Statistical analysis}

Statistical analysis was performed using IBM SPSS Statistics version 20 (IBM SPSS Inc., NY, USA). Quantitative data were expressed as means \pm standard deviations and compared using Student's t-tests or Mann-Whitney U tests, or for more than two groups by analysis of variance or Kruskal-Wallis tests. Qualitative variables were expressed as frequencies with percentages and compared using $\chi^{2}$ or Fisher's exact tests if conditions were missing, or for more than two groups by Freeman-Halton extension of Fisher's exact test.

Receiver operating characteristic (ROC) analyses were based on area under the curve (AUC), sensitivity (true positives/positives $[\mathrm{TP} / \mathrm{P}]$ ), specificity (true negatives/negatives $[\mathrm{TN} / \mathrm{N}]$ ), positive likelihood ratio (sensitivity/[100 - specificity]) and negative likelihood ratio ([1 - sensitivity]/specificity]).

All values were expressed as ranges (between 0 and 100), with 95\% CI. For all tests, two-sided p-values less than 0.05 were considered statistically significant.

\section{Results}

\section{Clinical features of the subjects}

During the 15-day study period, 60 subjects were admitted to the ED of La Timone Hospital with febrile symptoms. Their biological samples were all processed, but ten subjects had incomplete clinical files and did not satisfy the study criteria. Of the remaining 50 subjects definitively included in the study, 39 (78\%) were classified as having bacterial infections, whereas $4(8 \%)$ were classified as having viral infections. The seven (14\%) remaining subjects were classified as having no infection, although they were initially included in the study for febrile symptoms. The reason is that these subjects had more inflammatory than infectious pathologies. No subjects had bacterial and viral co-infections. An overview of the study workflow and pathologies' details in each group are shown in Figure 1.

\section{Epidemiology of infected subjects}

The 50 subjects in the final cohort included $25(50 \%)$ women and $25(50 \%)$ men, with a mean age of 57 $( \pm 24)$ years. All epidemiological data are presented in Table 1.

No significant differences were observed either for the sex balance, or for the mean age or for clinical histories of the subjects between bacterial and control (no infection) groups. However, subjects included in the viral infection group seemed having a mean age decreased from $56( \pm 21)$ to $28( \pm 14)$ years. Subject clinical features were similar 


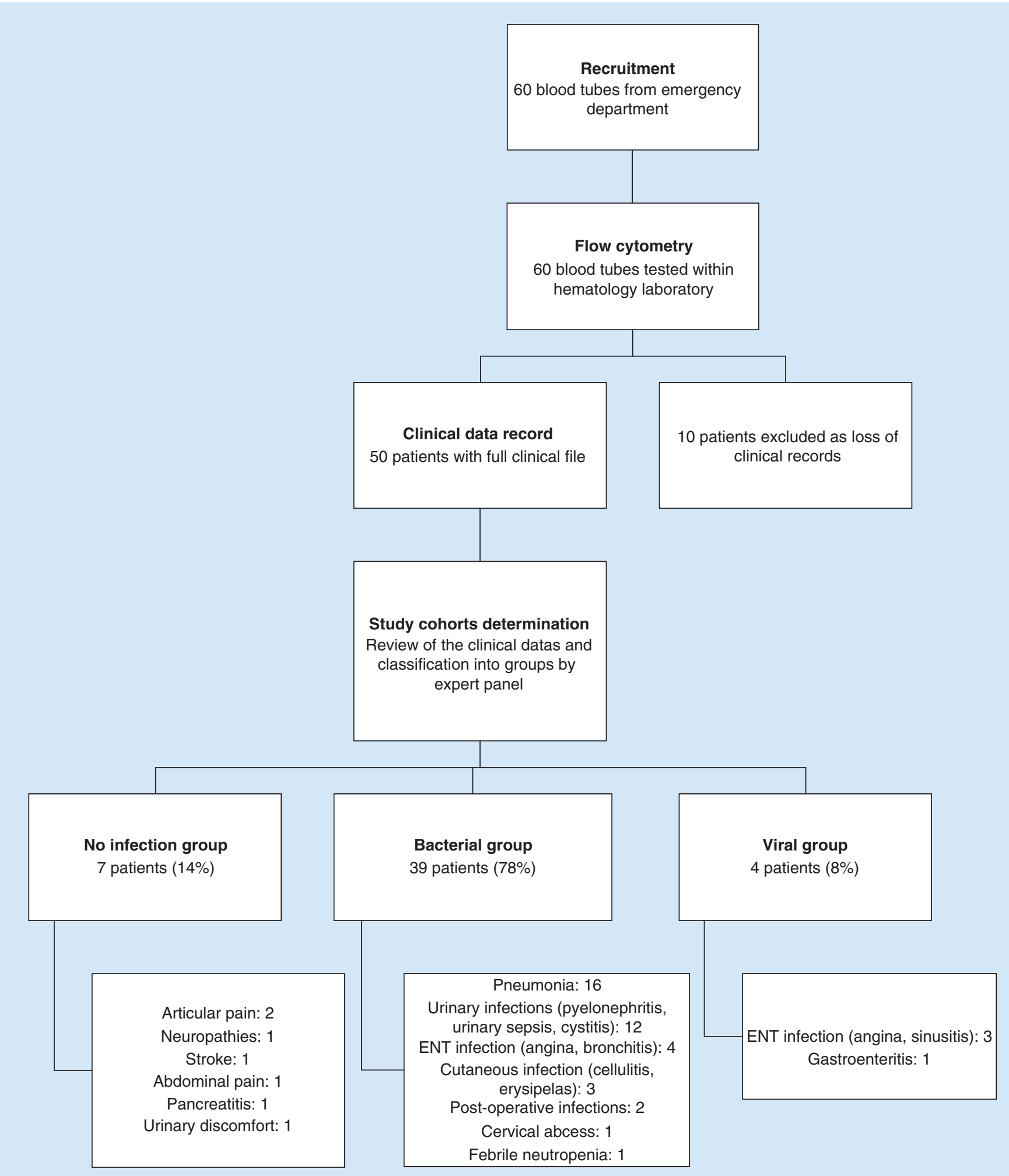

Figure 1. Overview of the study workflow. Construction tree of the prospective study conducted in the ED of La Timone Hospital, with final numbers and diagnoses for subjects who were admitted with febrile or acute symptoms.

ED: Emergency department; ENT: Ear, nose and throat. 
Table 1. Cohort study characteristics.

\begin{tabular}{|c|c|c|c|c|}
\hline Characteristic & No Infection group $(n=7)$ & Bacterial group $(n=39)$ & Viral group $(n=4)$ & $\begin{array}{l}\text { p-value (Bacterial vs no infection } \\
\text { group) }\end{array}$ \\
\hline \multicolumn{5}{|l|}{ Patient sex: } \\
\hline- Men & $3(43 \%)$ & $19(49 \%)$ & $3(75 \%)$ & 1.00 \\
\hline Patient age (years) & $56 \pm 21$ & $61 \pm 24$ & $28 \pm 14$ & 0.62 \\
\hline \multicolumn{5}{|l|}{ Clinical history: } \\
\hline - Evolutive cancer & $0(0 \%)$ & $2(5 \%)$ & $0(0 \%)$ & 1.00 \\
\hline - Liver disease & $0(0 \%)$ & $4(10 \%)$ & $0(0 \%)$ & 1.00 \\
\hline - Congestive heart failure & $1(14 \%)$ & $3(8 \%)$ & $0(0 \%)$ & 0.50 \\
\hline - Cerebrovascular disease & $0(0 \%)$ & $4(10 \%)$ & $0(0 \%)$ & 1.00 \\
\hline $\begin{array}{l}\text { - Diastolic blood pressure (mm } \\
\mathrm{Hg})\end{array}$ & $68 \pm 10$ & $73 \pm 16$ & $73 \pm 11$ & 0.45 \\
\hline - Pulse rate (bpm) & $79 \pm 16$ & $104 \pm 21$ & $90 \pm 7$ & $<0.01 *$ \\
\hline - Body temperature $\left({ }^{\circ} \mathrm{C}\right)$ & $37.1 \pm 0.9$ & $38.1 \pm 1.1$ & $38.4 \pm 2.2$ & 0.07 \\
\hline \multicolumn{5}{|l|}{ Clinical symptoms: } \\
\hline - Duration (days) & $4 \pm 5$ & $5 \pm 10$ & $2 \pm 2$ & 0.59 \\
\hline - Respiratory & $0(0 \%)$ & $21(54 \%)$ & $1(25 \%)$ & $0.03 *$ \\
\hline - Gastrointestinal & $2(29 \%)$ & $2(5 \%)$ & $1(25 \%)$ & \\
\hline - Urological/gynecological & $0(0 \%)$ & $2(5 \%)$ & $0(0 \%)$ & \\
\hline - Neurological & $1(14 \%)$ & $0(0 \%)$ & $1(25 \%)$ & \\
\hline
\end{tabular}

between bacterial and control groups, except that pulse rate was significantly increased from $79( \pm 16)$ to $104( \pm 21)$ bpm in the bacterial infection group $(\mathrm{p}<0.01)$.

A wide range of infectious symptoms was observed (respiratory, gastrointestinal, urological/gynecological, neurological, ear, nose and throat, cutaneous and postoperative), but significantly more frequently in subjects in the bacterial infection group ( $\mathrm{p}=0.03$ ). However, their time from onset was equivalent between the groups. The most common clinical presentation associated with bacterial infections was respiratory symptoms $(\mathrm{n}=21 ; 54 \%)$, whereas respiratory, gastrointestinal, neurological and ear, nose and throat symptoms were equivalently representative of viral conditions. As expected, subjects diagnosed as having bacterial infections were treated significantly more frequently with antibiotics $(n=27 ; 69 \% ; \mathrm{p}<0.01)$ than subjects with no infection. No differences were observed in hospitalization duration.

Finally, comparison of biochemical and biological measurements are presented in Table 2. Only hematocrit level showed statistically significant differences between bacterial and control groups $(\mathrm{p}=0.03)$.

Overall, 11 common pathogen species were detected (Table 3). The most common pathogens were Escherichia coli (28\%) and Klebsiella pneumonia (18\%). 


\begin{tabular}{|c|c|c|c|c|}
\hline Characteristic & No infection group $(n=7)$ & Bacterial group $(n=39)$ & Viral group $(n=4)$ & $\begin{array}{l}\text { p-value (Bacterial vs no infection } \\
\text { group) }\end{array}$ \\
\hline \multicolumn{5}{|l|}{ Biological measurements } \\
\hline White blood cells (g/l) & $11 \pm 3$ & $11 \pm 5$ & $7 \pm 2$ & 0.98 \\
\hline Polymorphonuclear cells (g/l) & $5.9 \pm 0.1$ & $7.4 \pm 5.4$ & $5.5 \pm 0.1$ & 0.76 \\
\hline \multicolumn{5}{|l|}{ Biochemical constants } \\
\hline Glucose (mmol/l) & $6 \pm 1$ & $8 \pm 5$ & $5 \pm 1$ & 0.30 \\
\hline Hematocrit (\%) & $41 \pm 3$ & $37 \pm 5$ & $42 \pm 3$ & $0.03 *$ \\
\hline
\end{tabular}

\section{Table 3. Identification of pathogens in the cohort study.}

Pathogen identified

Escherichia coli

Number isolated $(\mathrm{n}=11)$

Klebsiella pneumoniae

$3(28 \%)$

Staphylococcus aureus

$2(18 \%)$

Staphylococcus hominis

$1(9 \%)$

Staphylococcus epidermidis

$1(9 \%)$

Streptococcus pyogenes

$1(9 \%)$

Enterobacter clocacae

$1(9 \%)$

Haemophilus influenzae

$1(9 \%)$

Numbers of bacteria and viruses isolated and/or detected in blood culture, urinary culture or serological measurements.

\section{Table 4. Flow cytometry assessments.}

\begin{tabular}{|c|c|c|c|c|}
\hline Biomarkers' MFI & No infection group $(n=7)$ & Bacterial group $(n=39)$ & Viral group $(n=4)$ & $\begin{array}{l}\text { p-value (Bacterial vs no infection } \\
\text { group) }\end{array}$ \\
\hline nCD64 & $1 \pm 0$ & $2 \pm 1$ & $1 \pm 0$ & $<0.01 *$ \\
\hline $\mathrm{mCD} 169$ & $1 \pm 0$ & $1 \pm 3$ & $7 \pm 5$ & 0.19 \\
\hline $\mathrm{mCD} 35$ & $21 \pm 5$ & $31 \pm 11$ & $14 \pm 1$ & $0.02 *$ \\
\hline nCD35 & $19 \pm 4$ & $26 \pm 9$ & $12 \pm 3$ & $0.02 *$ \\
\hline $\mathrm{mCD} 55$ & $29 \pm 6$ & $45 \pm 14$ & $31 \pm 10$ & $<0.01 *$ \\
\hline nCD55 & $18 \pm 3$ & $26 \pm 8$ & $20 \pm 3$ & $<0.01 *$ \\
\hline $\mathrm{rHLA}-\mathrm{ABC}$ & $4 \pm 1$ & $4 \pm 1$ & $6 \pm 1$ & 0.27 \\
\hline $\mathrm{mCD} 46$ & $41 \pm 8$ & $47 \pm 15$ & $56 \pm 19$ & 0.47 \\
\hline $\mathrm{mCD} 14$ & $33 \pm 9$ & $39 \pm 9$ & $40 \pm 6$ & 0.06 \\
\hline mHLA-DR & $5 \pm 3$ & $6 \pm 5$ & $12 \pm 1$ & 0.96 \\
\hline ICD69 & $11 \pm 2$ & $15 \pm 7$ & $11 \pm 2$ & $0.03 *$ \\
\hline mCD69 & $10 \pm 2$ & $12 \pm 3$ & $11 \pm 1$ & 0.16 \\
\hline nCD69 & $9 \pm 2$ & $10 \pm 2$ & $9 \pm 1$ & $0.04 *$ \\
\hline
\end{tabular}

Mean offluorescence intensities are presented as mean \pm standard deviation for each biomarker.

${ }^{*} p$-values $\leq 5 \%$ statistically significant differences between groups.

mCD46: CD46 on monocyte; mCD55: CD55 on monocyte; mCD169: CD169 on monocyte; nCD55: CD55 on neutrophil; nCD64: CD64 on neutrophil; MFI: Mean fluorescence intensity.

\section{Biomarker levels \& ROC analysis}

In total, nine biomarkers were assessed using flow cytometry on 1-3 leukocyte subsets, resulting in monitoring of 13 parameters (Table 4). Example of flow cytometry expressions of nCD64 and mCD169 is given in Supplementary Figure 1.

Biomarkers known to be altered in the presence of bacterial infection include nCD64, $\mathrm{mCD} 35, \mathrm{nCD} 35$, mCD55 and $\mathrm{nCD} 55$; 1CD69, mCD69, nCD69, mCD14 and mHLA-DR may also be altered. Subjects with 
Table 5. PCT and C-reactive protein levels.

\begin{tabular}{|c|c|c|c|c|}
\hline Variable & No infection group $(n=7)$ & Bacterial group $(n=39)$ & Viral group $(n=4)$ & $\begin{array}{l}\text { p-value (Bacterial vs no infection } \\
\text { group) }\end{array}$ \\
\hline PCT (ng/l) & $0.07 \pm 0.08$ & $0.76 \pm 1.80$ & $0.04 \pm 0.03$ & 0.24 \\
\hline
\end{tabular}

Values are presented as mean \pm standard deviation.

${ }^{*} p$-values $\leq 5 \%$ statistically significant differences between groups.

bacterial infections had a significantly higher level of nCD64 (MFI of $2 \pm 1 ; \mathrm{p}<0.01$ ), mCD35 (MFI of $31 \pm 11$; $\mathrm{p}=0.02$ ), $\mathrm{nCD} 35$ (MFI of $26 \pm 9 ; \mathrm{p}=0.02), \operatorname{mCD} 55$ (MFI of $45 \pm 14 ; \mathrm{p}<0.01), \mathrm{nCD} 55$ (MFI of $26 \pm 8$; $\mathrm{p}<0.01$ ), 1CD69 (MFI of $15 \pm 7 ; \mathrm{p}=0.03$ ) and nCD69 (MFI of $10 \pm 2 ; \mathrm{p}=0.04$ ). Figure 2 shows their results of ROC analysis. Using a cut-off point of $\geq 0.96, \mathrm{nCD} 64$ MFI showed the best bacterial discriminative performance, with a sensitivity of $82 \%(66.5-92.5 \%)$, specificity of $91 \%(58.7-99.8 \%)$, positive likelihood ratio of 9.03 (1.4-58.8) and negative likelihood ratio of 0.20 (0.10-0.4). The AUC was $0.92(0.80-0.98)$. Numbers of true positive, false positive, false negative and true negative cases are detailed in Supplementary Table 1.

Conversely, biomarkers known to be altered in the presence of viral infection include mCD169, rHLA-ABC and mCD46; 1CD69, mCD69, nCD69, mCD14 and mHLA-DR may also be altered. Neither statistical comparison nor ROC analysis could have been performed due to the low number of viral infections, but subjects with viral infections seemed to have higher levels of mCD169 (MFI of $7 \pm 5$ ), rHLA-ABC (MFI of $6 \pm 1$ ) and mHLA-DR $($ MFI of $12 \pm 1)$.

\section{Comparison with CRP \& PCT}

For a comparison with previous cellular biomarkers, levels and ROC curves of CRP and PCT are presented in Table 5 \& Figure 3, respectively.

CRP level ( $p<0.01)$ was significantly higher in the bacterial infection group than in control group $(20 \pm 23$ to $86 \pm 74 \mathrm{mg} / \mathrm{l}$, respectively), whereas PCT level $(\mathrm{p}=0.24)$ was not significantly different between both groups $(0.07 \pm 0.08$ to $0.76 \pm 1.80 \mathrm{ng} / \mathrm{l})$.

For subjects with bacterial infections, the optimal cutoff for CRP was $\geq 33.1 \mathrm{mg} / \mathrm{l}$, with a sensitivity of $69 \%$ (52.4-83\%), specificity of $91 \%(58.7-99.8 \%)$ and AUC of 0.86 (0.73-0.94). The optimal cutoff for PCT was $\geq 0.02 \mathrm{ng} / \mathrm{l}$, with a sensitivity of $93 \%$ (76.5-99.1\%), specificity of $60 \%(14.7-94.7 \%)$ and AUC of $0.81(0.64-$ $0.93)$.

\section{Discussion}

In this observational, prospective, single-center study, 13 leukocytes parameters, in other words, nCD64, mCD169, mCD14, mCD35, nCD35, mCD46, mCD55, nCD55, lCD69, mCD69, nCD69, rHLA-ABC and mHLA-DR, were evaluated in subjects in the ED. The aim was to assess their expression levels using an innovative, 15-min, one-step method and evaluate correlations among expression levels with clinical parameters in subjects with or without bacterial or viral infections. CRP and PCT were also evaluated.

For many years, intense research of new biomarkers for stratification of infectious disease has been used for appropriate triage, management and treatment of subjects with systemic infections [6,17,26]. Biomarkers, CRP and PCT levels in each group were consistent with previous reports [17,18,27-29]. Notably, however, there were no significant differences in WBC or PMN counts, confirming the very poor performances of these markers. When analyzed with ROC models, only nCD64 showed effective discrimination between bacterial and nonbacterial infections. Conversely, mCD169, mHLA-DR and rHLA-ABC biomarkers seemed having higher values in viral than in nonviral infections. Nevertheless, this result needs to be confirmed in more cases because the number of subjects with viral infections was very low. Other tested leukocyte markers did not show satisfactory performance because none showed high sensitivity to ensure that the most subjects are identified and that cases of infection are not missed, and they did not have sufficiently high specificity either to ensure the infection etiology.

For nCD64, the discriminative power was higher than those found for reference assays. These results were not surprising because CRP level has been shown to be a sensitive, albeit nonspecific marker of inflammation with limited utility in the ED for identifying infection etiology in subjects with fever [30]. In contrast, PCT level shows strong sensitivity and specificity in subjects with systemic infections, such as severe sepsis, but are limited for 

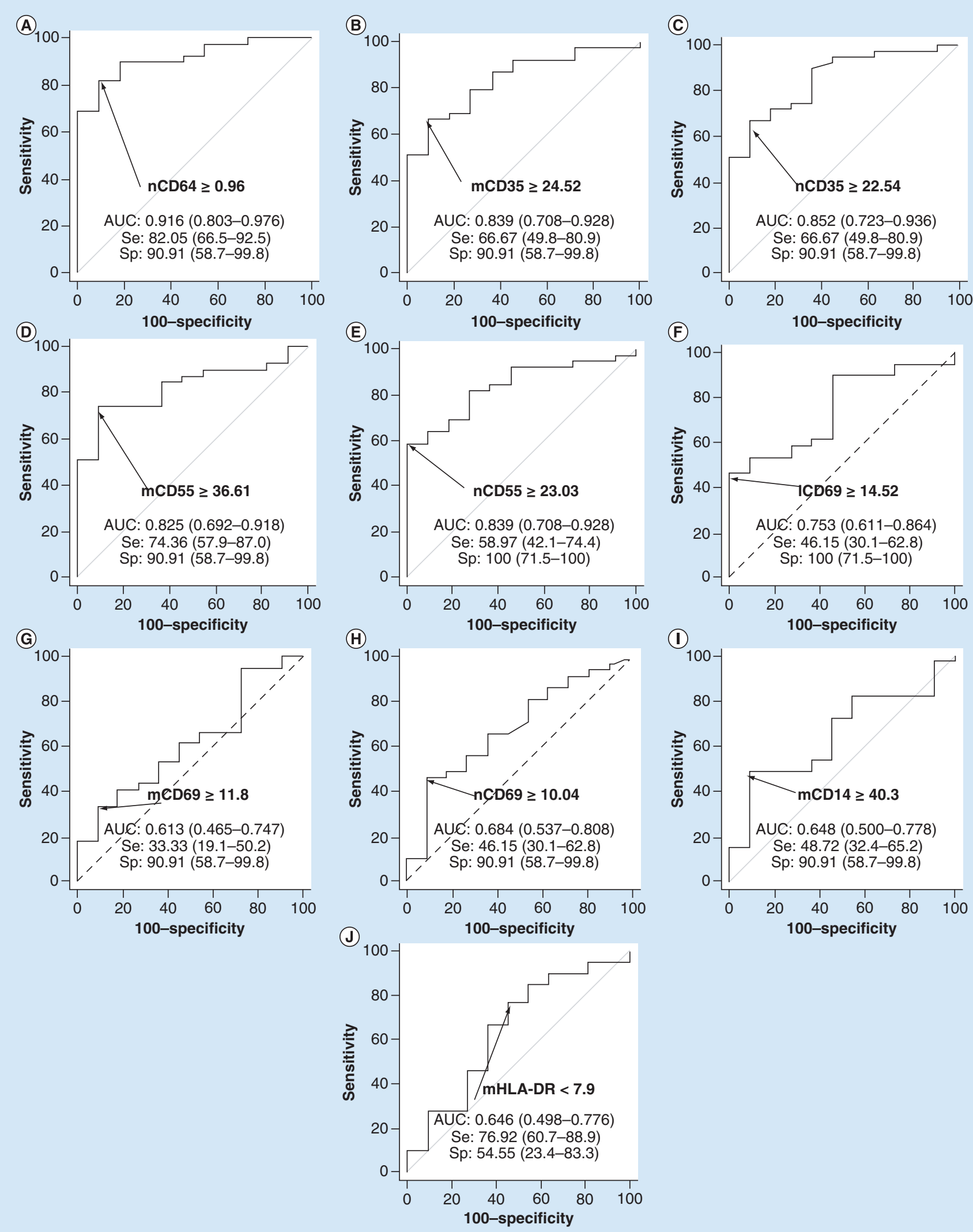

Figure 2. Receiver operating characteristic analysis for bacterial diagnosis. ROC curves for the discrimination of bacterial infections with (A) nCD64, (B) mCD35, (C) nCD35, (D) mCD55, (E) nCD55, (F) ICD69, (G) mCD69, (H) nCD69, (I) mCD14 and (J) mHLA-DR. Optimal thresholds for each biomarker are indicated with calculated values of $\mathrm{Sp}$ and $\mathrm{Se}$. AUCs and $95 \% \mathrm{Cl}$ are also given for each receiver operating characteristic analysis.

AUC: Area under curve; mCD55: CD55 on monocyte; mCD169: CD169 on monocyte; nCD55: CD55 on neutrophil; nCD64: CD64 on neutrophil; Se: Sensitivity; Sp: Specificity. 
(A)

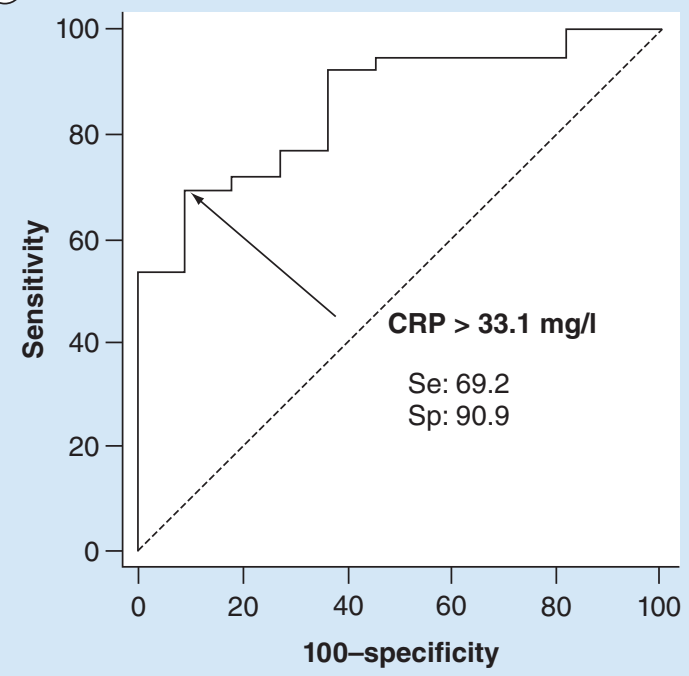

(B)

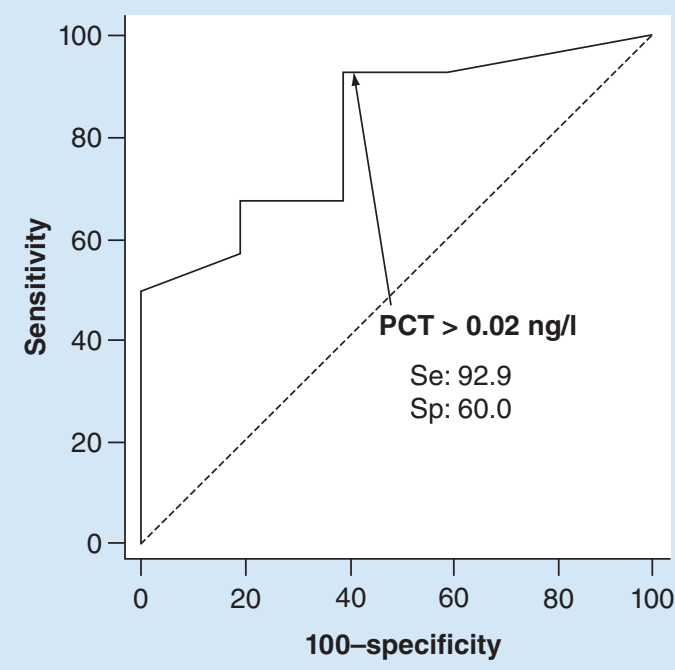

Figure 3. Receiver operating characteristic analysis for C-reactive protein and procalcitonin. (A) CRP and (B) PCT ROC curves for diagnosis of bacterial infections. Optimal thresholds are indicated with calculated values of Sp and Se. Se: Sensitivity; Sp: Specificity.

identifying local infections [31]. Overall, neither CRP nor PCT can be used to identify viral infections, because negative results for CRP or PCT are only suggestive of a nonbacterial etiology.

This study had some limitations. First, subjects were only enrolled from the ED, which may have resulted in selection bias. Additionally, groups were made up of individuals with various infectious diseases and degrees of severity, instead of being focused on only one type of pathology, as seen in other studies of infections [32-34]. Moreover, because this was an observational study, the ED team of experts was blinded to the flow cytometry results when establishing the diagnosis, but not to microbiological measurements of subject clinical data, which could have biased the classification of the subjects into groups [35-38] and no interventions were performed with regard to additional diagnostic assays for each subject. Because of this, very few subjects with confirmed bacterial or viral infections were included, and the proportion of subjects with viral infection was too low ( $8 \%$ of total cohort). The absence of microbiological confirmation may lead to higher rates of mislabeling [39]. Thus, the biomarkers relevance will have to be precisely assessed in future studies of more subjects with viral infection.

A single perfect reference standard is not easy to establish. Several strategies have to be considered, each with strengths and limitations [40]. Indeed, the study biomarkers may be useful for subjects with systemic infections, but could have limitations owing to their unknown kinetics in infected subjects. However, biomarkers such as nCD64 and mCD169 remain very promising as depending on early interferons production after bacteria or viruses infection $[13,28]$, and therefore having levels following disease progression. Moreover, it could be challenging for practitioners to reach a diagnosis on the basis of a single blood sample rather than sequential samples [26]. Additionally, MFI measurements by flow cytometry are strongly dependent on instrument setup, which will necessitate standardization efforts, in terms of calibration strategy and automation. Future research should focus on confirming these biomarkers on a larger scale and incorporating them as part of the overall clinical management of subjects with fever [41].

Finally, nCD64, mCD169, mHLA-DR and rHLA-ABC are not used in clinical practice yet. However, the ED environment is complex and dynamic and thus requires technologies tailored specifically for prevention of infection and enhancement of subject safety in emergency care. There is a lack of appropriate assays for improving infectious diagnostic capabilities and outcomes and for reducing the empirical use of antimicrobial drugs [1]. A solution to this may be the development of point-of-care diagnostic assays. The Dittrich et al. [42] highlighted the main requirements in a target product profile. One of the main achievements of this study was the use of the innovative flow cytometry protocol for assessing the levels of biomarkers [16]. This procedure, already demonstrated to give performances equivalent to standard flow cytometry procedure, may meet the minimum characteristics required 
for a bacterial versus viral test. Additionally, this assay yielded results in less than $15 \mathrm{~min}$ from whole blood samples. Although the study was conducted with EDTA-containing blood collection tubes containing several milliliters of material, only $5 \mu \mathrm{l}$ of the sample was required, potentially permitting the use of capillary blood from subjects. Reagent storage and laboratory procedures were carried out at room temperature. All steps for testing the samples were combined into one step, making this method technically easier than other approaches and allowing staff at health centers to be quickly trained. This simplified procedure combined with the biomarkers, should facilitate the discrimination between bacterial and viral infections.

\section{Conclusion}

In this study, we demonstrated the potential value of assessing levels of nCD64, and more preliminarily of mCD169, mHLA-DR and rHLA-ABC in subjects presenting at the ED, to predict bacterial versus viral causes of fever. As part of a global effort to improve subject care, biomarker levels were measured using an innovative, easy, rapid one-step flow cytometry procedure, that, in the ED setting, may represent a rapid, robust method to potentially inform triage and treatment decisions for a wide range of infections.

\section{Summary points}

- The identification of infectious etiology is a major challenge for emergency medicine.

- Assessment of infection-related biomarkers by a new rapid method could attribute a bacterial or viral or noninfectious origin to a febrile symptom.

- Expressions of CD64, CD169, CD35, CD55, CD46, HLA-ABC, CD14, HLA-DR and CD69 are measured by a point-of-care and rapid procedure of flow cytometry.

- Biomarker levels are measured within a prospective cohort of 50 subjects in the Emergency Department of La Timone Hospital, including $78 \%$ bacterial infections and $8 \%$ viral infections.

- CD64 on neutrophils shows $82 \%$ sensitivity and $91 \%$ specificity for identifying subjects in bacterial conditions, but other biomarkers had lower discriminative performances.

- CD64 on neutrophils (nCD64) performances are equivalent or even better than CRP and PCT assays, for which sensitivity of 69 and $93 \%$, and specificity of 91 and $60 \%$, respectively, were obtained.

- Levels of CD169 on monocytes (mCD169), HLA-ABC ratio and HLA-DR on monocytes appear to be higher in cases of viral infections.

- These encouraging preliminary results should be confirmed and extended through larger studies, encompassing as many infectious diseases as possible.

\section{Supplementary data}

To view the supplementary data that accompany this paper please visit the journal website at: www.futuremedicine.com/doi/sup $\mathrm{pl} / 10.2217 / \mathrm{fmb}-2019-0256$

\section{Author contributions}

PE Morange, I Arnoux, T Markarian and P Michelet contributed substantially to the conception and interpretation of the study. D Bernot, $\mathrm{P}$ Bourgoin and F Malergue contributed substantially to the acquisition and analysis of flow cytometry data, while $T$ Soliveres and D Ahriz contributed substantially to the retrieval of clinical data and interpretation. Each author either participated in drafting the work or revising it. Also, each author provided final approval of the version to be published, and agreed to be accountable for all aspects of the work.

\section{Acknowledgments}

The authors would like to thank the technician team from the Timone University Hospital Hematology Laboratory for their assistance in blood testing.

Financial \& competing interests disclosure

F Malergue and P Bourgoin are Beckman Coulter employees. P Bourgoin is recipient of a CIFRE PhD grant [number 2016/1368] from the ANRT (National Agency for Research and Technology). They provided critical advice on setup of the assay and instruments and in manuscript preparation. This study was partially supported by Beckman Coulter through donations of laboratory supplies and participation of the two employees mentioned. This private company had no role in the study design, or collection and interpretation of the clinical data. Beckman Coulter and the Beckman Coulter product and service marks mentioned herein are 
trademarks or registered trademarks of Beckman Coulter, Inc. in USA and other countries. All other trademarks are the property of their respective owners. The authors have no other relevant affiliations or financial involvement with any organization or entity with a financial interest in or financial conflict with the subject matter or materials discussed in the manuscript apart from those disclosed.

No writing assistance was utilized in the production of this manuscript.

\section{Ethical conduct of research}

The authors state that they have followed the principles outlined in the Declaration of Helsinki for all human experimental investigations. Routine care of the subjects was not modified; analyses were performed on anonymized blood left over, and all data collected in the study were part of routine clinical practice and retrieved from subject records. Results of the study had no influence on subjects' management.

\section{Data sharing statement}

The authors certify that this manuscript reports original clinical research data. Individual data that underlie the results reported in this article are available from the corresponding author following publication, including the study report and study protocol. Additional data are available upon reasonable request.

\section{References}

Papers of special note have been highlighted as: • of interest; $\bullet \bullet$ of considerable interest

1. Liang SY, Theodoro DL, Schuur JD, Marschall J. Infection prevention in the Emergency Department. Ann. Emerg. Med. 64(3), 299-313 (2014).

2. Hassan U, Ghonge T, Reddy Jr. B et al. A point-of-care microfluidic biochip for quantification of CD64 expression from whole blood for sepsis stratification. Nat. Commun. 8, 1-12 (2017).

3. Ventola CL. The antibiotic resistance crisis. Pharm. Ther. 40(4), 277-283 (2015).

- Gives an overview of the antibiotic resistance issue, with a global understanding on its causes and future threats at a worldwide level.

4. Bartlett JG, Gilbert DN, Spellberg B. Seven ways to preserve the miracle of antibiotics. Clin. Infect. Dis. 56(10), 1445-1450 (2013).

5. Sklavou R, Karavanaki K, Critselis E et al. Variation of serum C-reactive protein (CRP) over time in pediatric cancer patients with febrile illness and its relevance to identified pathogen. Clin. Biochem. 45(15), 1178-1182 (2012).

6. Kapasi AJ, Dittrich S, González IJ, Rodwell TC. Host biomarkers for distinguishing bacterial from non-bacterial causes of acute febrile illness: a comprehensive review. PLOS ONE 11(8), 1-29 (2016).

- This comprehensive review summarizes the diagnostic performances of host biomarkers capable of differentiating bacterial from nonbacterial infections to guide use of antibiotics.

7. Bourgoin P, Soliveres T, Ahriz D et al. Clinical research assessment by flow cytometry of biomarkers for infectious stratification in an Emergency Department. BiomarkMed 13(16), 1373-1386 (2019).

- This retrospective study introduces the first results of CD64 on neutrophils (nCD64) and CD169 on monocytes(mCD169) clinical evaluation with a new one-step procedure for flow cytometry.

8. Li S, Huang X, Chen Z et al. Neutrophil CD64 expression as a biomarker in the early diagnosis of bacterial infection: a meta-analysis. Int. J. Infect. Dis. 17(1), e12-e23 (2013).

- This meta-analysis reveals that $\mathrm{CD64}$ on neutrophils (nCD64) is a promising biomarker for diagnosing bacterial infections.

9. Xiong SD, Pu L-F, Wang HP et al. Neutrophil CD64 Index as a superior biomarker for early diagnosis of infection in febrile patients in the hematology department. Clin. Chem. Lab. Med. 55(1), 82-90 (2017).

10. Cid J, Aguinaco R, Sánchez R, García-Pardo G, Llorente A. Neutrophil CD64 expression as marker of bacterial infection: a systematic review and meta-analysis. J. Infect. 60(5), 313-319 (2010).

11. van der Kuyl AC, van den Burg R, Zorgdrager F, Groot F, Berkhout B, Cornelissen M. Sialoadhesin (CD169) expression in CD14+ cells is upregulated early after HIV-1 infection and increases during disease progression. PLoS ONE 2(2), e257 (2007).

12. Kim WK, McGary CM, Holder GE et al. Increased expression of CD169 on blood monocytes and its regulation by virus and CD8 T cells in macaque models of HIV infection and AIDS. AIDS Res. Hum. Retroviruses 31(7), 696-706 (2015).

13. Rempel H, Calosing C, Sun B, Pulliam L. Sialoadhesin expressed on IFN-induced monocytes binds HIV-1 and enhances infectivity. PLoS ONE 3(4), 1-9 (2008).

14. Ashokkumar C, Gabriellan A, Ningappa M, Mazariegos G, Sun Q, Sindhi R. Increased monocyte expression of sialoadhesin during acute cellular rejection and other enteritides after intestine transplantation in children. Transplantation 93(5), 561-564 (2012).

- Indicates that CD169 could be a biomarker of HIV and EBV infections in humans. 
15. Demaret J, Saison J, Venet F et al. Assessment of a novel flow cytometry technique of one-step intracellular staining: example of FOXP3 in clinical samples. Cytometry B Clin. Cytom. 84B(3), 187-193 (2013).

16. Bourgoin P, Hayman J, Rimmelé T, Venet F, Malergue F, Monneret G. A novel one-step extracellular staining for flow cytometry: proof-of-concept on sepsis-related biomarkers. J. Immunol. Methods 470, 59-63 (2019).

- This proof-of-concept study introduces the new one-step procedure for flow cytometry, feasible at the point-of-care and giving results in less than 15 min.

17. Nuutila J, Jalava-Karvinen P, Hohenthal U et al. A rapid flow cytometric method for distinguishing between febrile bacterial and viral infections. J. Microbiol. Methods 92(1), 64-72 (2013).

18. Nuutila J, Jalava-Karvinen P, Hohenthal U et al. Use of complement regulators, CD35, CD46, CD55, and CD59, on leukocytes as markers for diagnosis of viral and bacterial infections. Hum. Immunol. 74(5), 522-530 (2013).

19. Chalupa P, Beran O, Herwald H, Kaspř́ková N, Holub M. Evaluation of potential biomarkers for the discrimination of bacterial and viral infections. Infection. 39(5), 411-417 (2011).

20. Pitoiset F, Cassard L, El Soufi K et al. Deep phenotyping of immune cell populations by optimized and standardized flow cytometry analyses: deep immunophenotyping for clinical studies. Cytometry A 93(8), 793-802 (2018).

21. Pitoiset $\mathrm{F}$, Barbié $\mathrm{M}$, Monneret $\mathrm{G}$ et al. A standardized flow cytometry procedure for the monitoring of regulatory $\mathrm{T}$ cells in clinical trials: a standardized method to monitor Tregs. Cytometry B Clin. Cytom. 94(5), 621-626 (2018).

22. Hedley BD, Keeney M, Popma J, Chin-Yee I. Novel lymphocyte screening tube using dried monoclonal antibody reagents. Cytometry $B$ Clin. Cytom. 88(6), 361-370 (2015).

23. Rajab A, Axler O, Leung J, Wozniak M, Porwit A. Ten-color 15-antibody flow cytometry panel for immunophenotyping of lymphocyte population. Int. J. Lab. Hematol. 39, 76-85 (2017).

24. Correia RP, Rajab A, Bento LC et al. A ten-color tube with dried antibody reagents for the screening of hematological malignancies. Int. J. Lab. Hematol. 40(2), 136-143 (2018).

25. Jamin C, Le Lann L, Alvarez-Errico D et al. Multi-center harmonization of flow cytometers in the context of the European "PRECISESADS" project. Autoimmun. Rev. 15(11), 1038-1045 (2016).

26. Hausfater P, Juillien G, Madonna-Py B, Haroche J, Bernard M, Riou B. Serum procalcitonin measurement as diagnostic and prognostic marker in febrile adult patients presenting to the emergency department. Crit. Care 11(3), R60 (2007).

27. Hu L, Shi Q, Shi M, Liu R, Wang C. Diagnostic value of PCT and CRP for detecting serious bacterial infections in patients with fever of unknown origin: a systematic review and meta-analysis. Appl. Immunohistochem. Mol. Morphol. 25(8), e61-e69 (2017).

28. Mokuda S, Doi O, Takasugi K. Simultaneous quantitative analysis of the expression of CD64 and CD35 on neutrophils as markers to differentiate between bacterial and viral infections in patients with rheumatoid arthritis. Mod. Rheumatol. 22(5), $750-757$ (2012).

29. Pino M, Erkizia I, Benet S et al. HIV-1 immune activation induces Siglec-1 expression and enhances viral trans-infection in blood and tissue myeloid cells. Retrovirology 12(1), 1-15 (2015).

30. Weh J, Antoni C, Weiß C, Findeisen P, Ebert M, Böcker U. Discriminatory potential of C-reactive protein, cytokines, and fecal markers in infectious gastroenteritis in adults. Diagn. Microbiol. Infect. Dis. 77(1), 79-84 (2013).

31. Meisner M. Update on procalcitonin measurements. Ann. Lab. Med. 34(4), 263-273 (2014).

32. Cuquemelle E, Soulis F, Villers D et al. Can procalcitonin help identify associated bacterial infection in patients with severe influenza pneumonia? A multicentre study. Intensive Care Med. 37(5), 796-800 (2011).

33. Pfister R, Kochanek M, Leygeber T et al. Procalcitonin for diagnosis of bacterial pneumonia in critically ill patients during $2009 \mathrm{H} 1 \mathrm{~N} 1$ influenza pandemic: a prospective cohort study, systematic review and individual patient data meta-analysis. Crit. Care 18(2), R44 (2014).

34. Haran JP, Beaudoin FL, Suner S, Lu S. C-reactive protein as predictor of bacterial infection among patients with an influenza-like illness. Am. J. Emerg. Med. 31(1), 137-144 (2013).

35. Tang BM, Eslick GD, Craig JC, McLean AS. Accuracy of procalcitonin for sepsis diagnosis in critically ill patients: systematic review and meta-analysis. Lancet Infect. Dis. 7(3), 210-217 (2007).

36. Ray P, Badarou-Acossi G, Viallon A et al. Accuracy of the cerebrospinal fluid results to differentiate bacterial from non bacterial meningitis, in case of negative Gram-stained smear. Am. J. Emerg. Med. 25(2), 179-184 (2007).

37. Bossuyt PM, Reitsma JB, Bruns DE et al. Towards complete and accurate reporting of studies of diagnostic accuracy: the STARD initiative. BMJ 326(7379), 41-44 (2003).

38. Fischer JE, Bachmann LM, Jaeschke R. A readers' guide to the interpretation of diagnostic test properties: clinical example of sepsis. Intensive Care Med. 29(7), 1043-1051 (2003).

39. Srugo I, Klein A, Stein M et al. Validation of a novel assay to distinguish bacterial and viral infections. Pediatrics 140(4), e20163453 (2017).

40. Oved K, Cohen A, Boico O et al. A novel host-proteome signature for distinguishing between acute bacterial and viral infections. PLOS ONE 10(3), e0120012 (2015). 
41. Tang Z, Qin D, Tao M et al. Examining the utility of the CD64 index compared with other conventional indices for early diagnosis of neonatal infection. Sci. Rep. 8(1), 1-7 (2018).

42. Dittrich S, Tadesse BT, Moussy F et al. Target product profile for a diagnostic assay to differentiate between bacterial and non-bacterial infections and reduce antimicrobial overuse in resource-limited settings: an expert consensus. PLOS ONE 11(8), e0161721 (2016).

- This expert consensus defines a target product profile with associated requirements for a bacterial versus nonbacterial assay to guide future products' developments. 